\title{
A PRÁTICA DA DERIVA E OS FOTÓGRAFOS OCULTOS
}

\author{
Ítalo Franco Costa (Acadêmico/UFPel) \\ italofrancocosta@gmail.com \\ Cláudia Mariza Mattos Brandão (Orientadora/UFPel) \\ attos@vetorial.net
}

\section{RESUMO}

Este trabalho tem por objetivo discutir a prática da Carto/Foto/Graphia, utilizando os registros da fotógrafa Vivian Maier (BRANDÃO, 2016), da metade final do século XX, e as fotografias do acadêmico Ítalo Franco, relacionando-as e discutindo sobre a importância da percepção do local em que se vive, a fim de estimular o senso crítico sobre a realidade, necessário para que os sujeitos possam filtrar as imagens que perpassam o cotidiano. A discussão integra as ações do projeto de pesquisa "DO PÍNCEL AO PÍXEL: sobre as (re)apresentações de sujeitos/mundo em imagens", desenvolvido no âmbito do PhotoGraphein - Núcleo de Pesquisa em Fotografia e Educação (UFPel/CNPq), que tem como objetivo refletir sobre a fotografia como um recurso de representação das pessoas e dos seus percursos (auto)biográficos, e, principalmente, de criação e acumulação de conhecimentos produzidos sobre os sujeitos/fotógrafos e seus imaginários.

Palavras-chave: Fotografia; Carto/Foto/Graphia; Cidade; Vivian Maier.

\section{INTRODUÇÃO}

Quando pensamos sobre a relação dos indivíduos com as cidades, locais de maior concentração populacional, nós estamos refletindo sobre as suas práticas cotidianas: os caminhos percorridos, as pessoas com quem se relacionam e os locais com os quais se identificam e frequentam. Porém, mergulhados em seus afazeres, os cidadãos se transformam cada vez mais em agentes passivos com relação ao meio ao redor, por vezes distanciados da realidade local e fascinados com a espetacularização das cidades (JACQUES, 2005). Para alguns, a rotina é tão agitada que o tempo para perceber o contexto é limitado, muitas vezes o interesse está em frequentar os espaços mais conhecidos das cidades, locais já planejados para socialização, fazendo com que a verdadeira identidade da cidade se apague da memória coletiva com o passar do tempo.

A espetacularização das cidades está "diretamente relacionada a uma diminuição da participação popular, mas também a própria experiência física urbana enquanto prática cotidiana, estética ou artística" (JACQUES, 2005, p.1). Isso, somado à popularização da prática fotográfica em função das novas tecnologias, no final do século XX, proporcionou um aumento na produção de imagens, fazendo com que o indivíduo passasse da condição de criador a de reprodutor de imagens. Sendo assim, temos replicações de vários "cartões-postais" das cidades em uma atividade quase turística, é fotografado o que é posto para ser visível, a parte que deve ser mostrada para o mundo, ou seja, a superfície das relações urbanas: 
De fato, nas políticas e nos projetos urbanos contemporâneos, principalmente dentro da lógica do planejamento estratégico, existe uma clara intenção de se produzir uma imagem singular de cidade. Essa imagem seria fruto de uma cultura própria, da dita "identidade" da cidade, mas, paradoxalmente, essas imagens de cidades distintas, com culturas distintas, se parecem cada vez mais (JACQUES, 2005, p.2).

Este artigo discute sobre uma prática de pesquisa, a Carto/Foto/Graphia, desenvolvida no PhotoGraphein - Núcleo de Pesquisa em Fotografia e Educação, UFPel/CNPq, desde 2010. Em oposição ao processo de espetacularização, buscamos através dessa metodologia provocar as mentes e instigar os olhares, dando "visibilidade" às sensibilidades que afloram das cartas urbanas. Através de uma leitura sensível da cidade, pelo viés da fotografia, objetivamos a construção coletiva de um microcosmo simbólico, apresentado como uma cartografia do sensível, cuja significação surgirá com a compreensão das intrínsecas relações entre o fenômeno (a cidade), o sujeito e sua história. Assim, discutimos as diferentes percepções sobre o espaço urbano, relacionando a objetividade das representações cartográficas com as subjetividades que habitam a cidade, ou seja, promovemos leituras de mundo nas entrelinhas da produção artística.

O PhotoGraphein desenvolve pesquisas voltadas para as vivências cotidianas da cultura urbana e seus imaginários. Em tais investigações a linguagem fotográfica está associada aos processos educativos e de formação docente, relacionados ao desenvolvimento dos sujeitos contemporâneos e suas representações. Buscamos novas maneiras de perceber o familiar, desenvolvendo propostas que não se atém somente às possibilidades documentais dos materiais fotográficos. Nesse sentido, priorizamos intervenções que consideram a vivência e a cultura urbana, nas quais a imagem fotográfica é considerada um produto artístico/documental, num terreno alargado de possibilidades que manifesta os imaginários, pessoais e sociais.

Diferente da prática cartográfica com base nas ideias de Deleuze e Guatarri, que visa acompanhar um processo, e não representar um objeto (KASTRUP, 2009), a Carto/Foto/Graphia busca o registro da simbologia do vivido, reescrevendo através de imagens a experiência da deriva, proposta por Guy Debord (1960), que pode ser definida como "uma técnica do andar sem rumo sob a influência dos cenários" (BRANDÃO, 2013, p. 1), produzindo sua "arte total" através da relação com a cidade em uma participação de franca dedicação com o meio, de modo que se "viva diretamente" a experiência.

Para o desenvolvimento da discussão aqui proposta, nós utilizamos algumas produções da fotógrafa Vivian Maier e do acadêmico Ítalo Franco, bolsista PIBIC do projeto de pesquisa "DO PÍNCEL AO PÍXEL: sobre as (re)apresentações de sujeitos/mundo em imagens", e pesquisador do PhotoGraphein. Em comum tais imagens têm o foco no cotidiano urbano e, embora distanciadas no tempo, elas possuem vínculos simbólicos que nos permitem (re)significar ideias e comportamentos, (re)visitar imaginários e (re)construir a história pelo viés da produção fotográfica.

\section{SOBRE FOTÓGRAFOS OCULTOS}

Quando pensamos em "fotógrafos ocultos" podemos relacionar com o imaginário da pessoa que, com a câmera em mãos, fotografa o objeto de interesse sem chamar a atenção sobre si, a fim de captar uma espontaneidade que não se encontraria 
caso desse ser notado, visto que alguns temem a desaprovação da câmera. Porém, consideramos que um fotógrafo oculto não pode ser reduzido apenas a tal situação. Atraído pelo que é diferente, o fotógrafo oculto registra aquilo que é alheio a sua realidade, fugindo da normatividade de um mundo polarizado entre a sociedade espetacular e os moradores das cidades, fragmentando-o em diversas alegorias, transformando-o em um "mundo em miniatura", onde as pequenas relações que beiram o banal são o que há de mais valioso. Logo, o fotógrafo oculto acaba assim por vestir a roupagem de um personagem, alguém que através do uso da câmera apropria-se da coisa fotografada e põe "a si mesmo em determinada relação com o mundo, semelhante ao conhecimento - e, portanto, ao poder" (SONTAG, 2004. p.8) de estar alheio aos condicionamentos históricos e sociais.

Portanto, consideramos que os fotógrafos ocultos são semelhantes ao personagem do Flanêur (ARANTES, 2000), criado por Baudelaire e ressignificado por Benjamin, que seria ao mesmo tempo ator e espectador, que "submetido ao ritmo de seu próprio devaneio, (...) sobrepõe o ócio ao "lazer" e resiste ao tempo matematizado da indústria" (D'ANGELO, 2004, p.6). E desse modo tal figura sorveria inspiração para sua arte (no caso, a poesia) através da resistência à divisão esquizofrênica do espaço moderno, de uma nova Paris da Revolução Industrial do final do século XIX.

Por um lado, o Flâneur é o preguiçoso, o desperdiçador; por outro é o observador ou o detetive, a pessoa suspeita que está sempre olhando, observando e classificando (...) O Flâneur busca uma imersão nas sensações da cidade, "banhar-se na multidão", perder-se nas sensações, sucumbir ao arrasto de desejos aleatórios" (ARANTES, 2000, p. 192).

Diferente do personagem de Baudelaire que usa a tinta e o papel, o Fotógrafo Oculto usa a câmera fotográfica para desvelar o cotidiano e suas banalidades, "entretanto, é preciso ter claro que a temática do cotidiano não é apenas fruto de uma construção intencional do autor, de sua postura filosófica, ela permeia o próprio material por ele utilizado" (ORTIZ, ANO, p.4), ou seja, as cidades. E são fotógrafos ocultos que nos ajudaram neste artigo a discutir práticas da carto/foto/graphia que aproximam tempos e imaginários distantes no tempo.

Vivian Maier (1926-2009) se tornou relevante no mundo da fotografia, após o historiador John Maloof encontrar em um leilão, no ano de 2007, cerca de 3.500 negativos produzidos por ela, pouco tempo depois de sua morte. Entre eles haviam fotografias de muita sensibilidade e qualidade técnica, que retratam o cotidiano, principalmente da segunda metade do século XX, das cidades em que Maier viveu/conheceu, em especial New York e Chicago (MALOOF; SISKEL, 2014).

A divulgação de seus registros se deu através de exposições em pequenas galerias de arte. E o público ficou fascinado com a sua percepção das ruas, pela quantidade de registros produzidos pela babá, que não se reconhecia como uma fotógrafa, mantendo os seus negativos ocultos das pessoas, inclusive das famílias com quem trabalhou. Graças à qualidade técnica de suas fotos, logo Vivian foi consagrada no mundo da fotografia, pois nas palavras de Joel Meverowitz (MALOOF; SISKEL, 2014): "Parece que há um olho autêntico de um real conhecedor da natureza humana, da fotografia e das ruas (...), mas o trabalho de Vivian instantaneamente mostra aquelas qualidades da compreensão humana, do calor e da graciosidade que eu pensei - esta é uma verdadeira fotógrafa". E por isso ela se tornou uma conhecedora mais profunda das cidades em que viveu, principalmente de New York (Figura 1). 


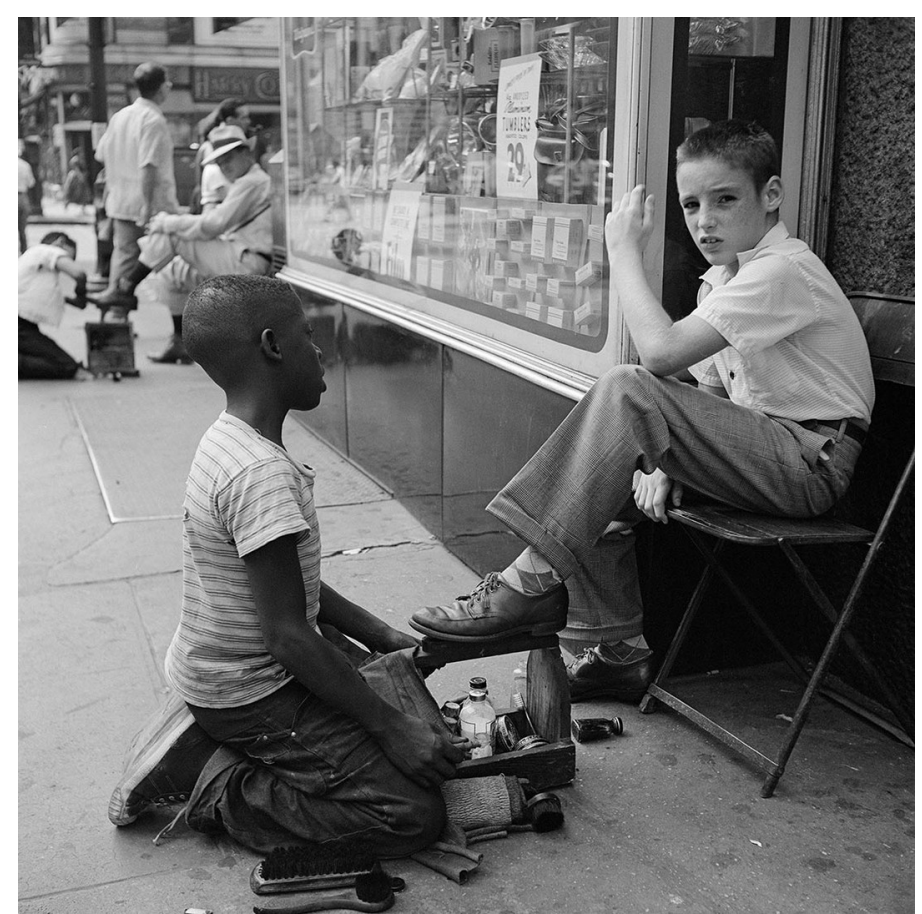

Figura 1: Vivian Maier, New York, fotografia analógica, 1954. Fonte: http://www.vivianmaier.com/

Os temas das fotografias de Maier incluem crianças, pedestres, situações triviais que poderiam passar despercebidas a outros, mas que para ela eram singulares, merecedores de registros sobre a realidade social e política de seu tempo. Muitas das suas imagens possuem um profundo cunho social e político, como o da Figura 1, na qual um menino negro engraxa o sapato de um menino branco. A imagem é perpassada pelo o imaginário da década de 50, evidenciando a questão do racismo e da desigualdade social entre negros e brancos no período. Tema que se mantém presente na sociedade até hoje, ou seja, o discurso presente na fotografia não perdeu sua vitalidade mesmo depois de cinco décadas.

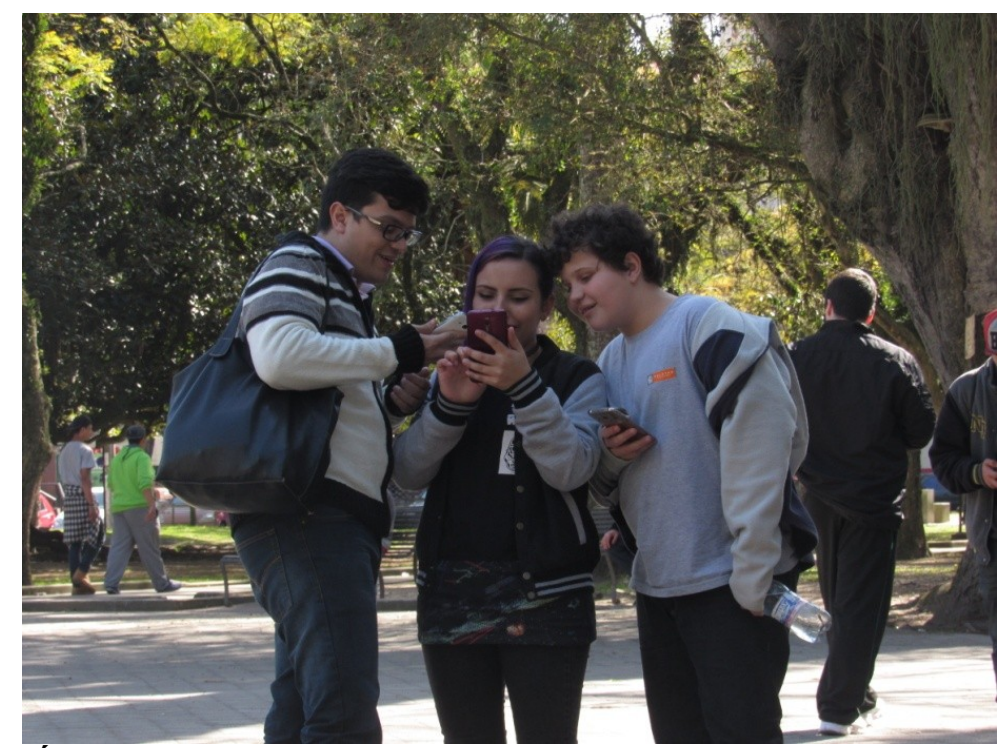

Figura 2: Ítalo Franco, Pelotas, Praça Coronel Pedro Osório, fotografia digital, 2016. 
$\mathrm{Na}$ Figura 2 um grupo de jovens se diverte jogando "Pokémon GO", diferente da atividade formal que o menino registrado por Maier (Figura 1) realiza. Isto nos faz perceber que a tecnologia trouxe uma infinita gama de possibilidades para o público jovem, mas que em países com desigualdade social pronunciada como no Brasil, fica evidenciado que apenas alguns se beneficiam, uma vez que nem todos tem um aparelho celular bom o suficiente para usar o aplicativo que durante um período foi uma febre entre os fãs da franquia Pokémon.

Distanciadas no tempo, essas duas imagens tornam visíveis imaginários sociais que nos falam sobre as mentalidades que determinam comportamentos. Além disso, elas nos levam a questionar as transformações ocorridas: será que algo mudou nos EUA no que tange à questão racial? Será que os jovens brasileiros vivenciam tais questões? Frente aos últimos acontecimentos na América do Norte, chegamos a pensar em agravamento dos conflitos raciais. Talvez no Brasil isso não seja tão visível, entretanto, sabemos bem que a questão racial perpassa a nossa sociedade, agravada pelas questões econômicas que principalmente atingem as classes mais baixas. Ou seja, por consequência é possível também pensar no efeito alienante que o divertimento propiciado pelas novas tecnologias pode provocar, acentuando ainda mais as diferenças sociais.

O pensamento humano é governado pela representação, ou seja, pelos símbolos que articulamos através de nossas culturas e vivências. Pode-se dizer que o "imaginário" e seus "símbolos" permeiam os ambientes, configurando os pensamentos. Eles não podem ser separados, sendo o primeiro um "conector necessário pelo qual se constitui toda representação humana" (DURAND, 2001 p. 16).

O imaginário, museu de todas as imagens do homem, de acordo com Durand, era antes controlado através da fé. A igreja com seus santos, cenários dualistas de céu e inferno, bem e mal, regia o mundo das imagens e, portanto, o mundo dos símbolos presentes no cotidiano da época. Contudo, com o avançar dos séculos e da tecnologia o imaginário passa a ser de domínio das grandes corporações, emissoras de televisão, cinema, belas artes, imprensa e grandes empresas. As imagens que antes eram limitadas às igrejas, passaram a ser utilizadas em todas as esferas sociais, sendo que a sua produção desenfreada trará consequências classificadas por Durand (2001) como um "Efeito Perverso", em sociedades cada vez mais dependentes das imagens. Portanto, desafiar o domínio da imagem através da revalorização do imaginário, é um desafio a que nos propomos, conscientes da necessidade de se perceber o mundo, de vivenciar a cidade como um espaço repleto de experiências sensoriais escondidas embaixo do espetacular. Além disso, aproximar as nossas experiências de outras distanciadas no tempo, possibilitam a reflexão crítica sobre o mundo.

O considerável número de fotografias produzidas por Vivian Maier é um reflexo de seu tempo, pois "durante o quarto de século que se seguiu à Segunda Guerra Mundial, a extraordinária ascensão da fotografia se fez acompanhar de uma abertura eufórica, sem limites, sem reservas, à imagem" (ROUILLÉ, 2009, p.140). Observar as fotografias apresentadas neste texto é uma experiência de imersão e também de compreensão do imaginário norte-americano dos anos 50 do século XX. Ela fotografava freneticamente o cotidiano, e seus registros são como mapas das suas caminhadas/derivas, passivas de interpretação. Assim, é possível discutir acerca da fotografia como um recurso de representação das pessoas e dos seus percursos (auto)biográficos. E nesse sentido, a imagem se torna um registro de conhecimentos dos/sobre os sujeitos/fotógrafos e seus imaginários.

Para nós, pesquisadores do Photographein, no exercício da Carto/Foto/Graphia, as imagens de Maier não são somente registros visuais, como pretende o método 
cartográfico proposto por Kastrup, com base nas ideias de Guatarri e Deleuze, são, sim, registros simbólicos repletos de significados, que nos possibilitam discutir sobre imaginários, aproximando-os da realidade contemporânea.

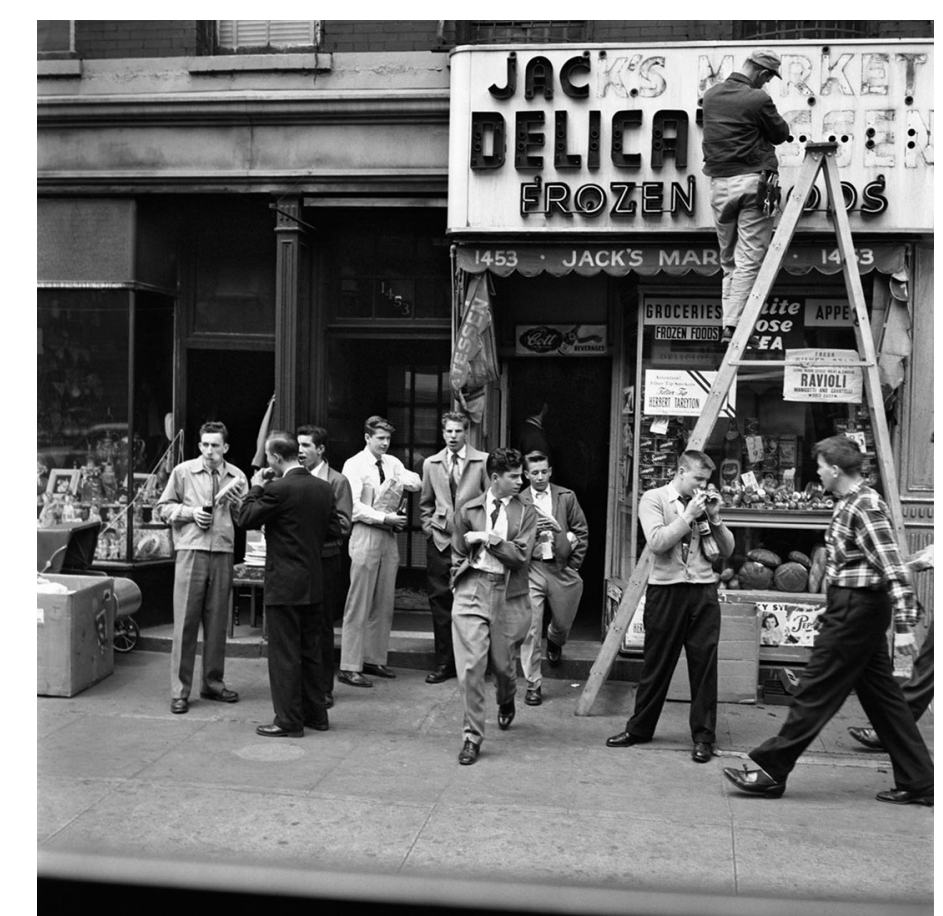

Figura 3: Vivian Maier, New York, NY, fotografia analógica, 1956. Fonte: http://www.vivianmaier.com/

Não apenas a forma como as cidades se erguem, mas também como e onde as pessoas se relacionam são temas recorrentes nas fotografias de Maier (Figura 3). Na imagem percebemos um grupo de homens se alimentando em frente a um mercado de frozen food, e nele não identificamos mulheres. Na década de 50 o espaço na sociedade para homens e mulheres era bastante delimitado: às mulheres eram destinadas atividades ditas "do lar" e aos homens o emprego que garantia a renda familiar, pois cabia a eles sustentá-la. E tal simbolismo está expresso no instantâneo de Maier.

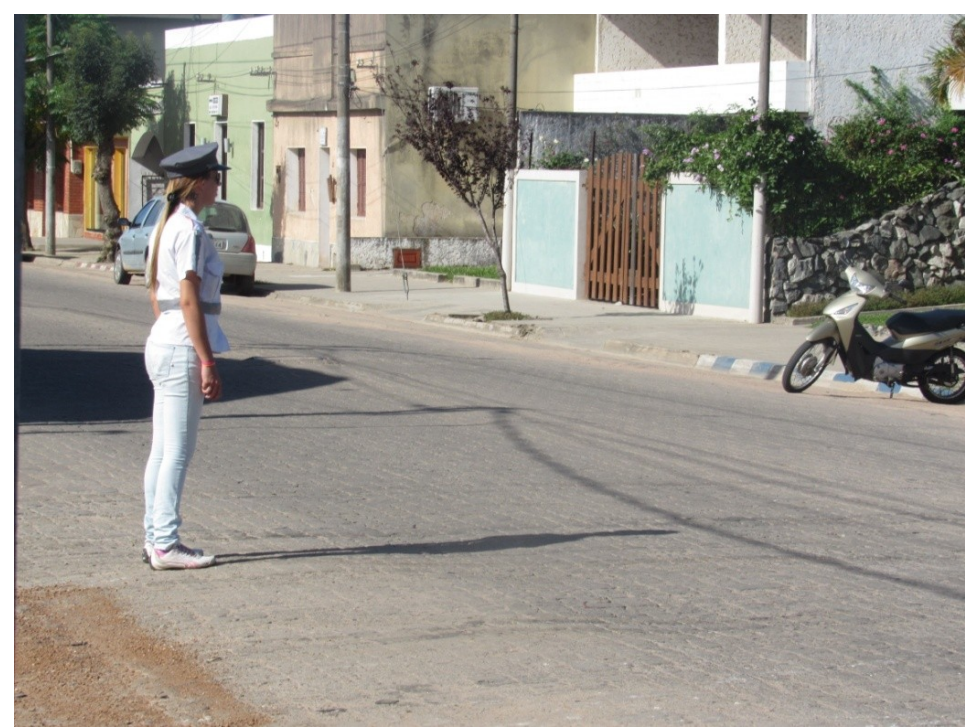

Figura 4: Ítalo Franco, Guarda de Trânsito em Rio Branco, fotografia digital, 2016. 
Hoje a desigualdade entre o sexo masculino e feminino diminuiu, mas não deixou de existir. As mulheres têm mais oportunidades na área de trabalho e podemos vê-las ocupando cargos/espaços que há cinquenta anos não seria possível, como mostra a Figura 4. Entretanto, embora imagens do cotidiano contemporâneo nos acenem para transformações, sabemos que a situação ainda exige um estado de atenção, visto que em nosso país a desigualdade entre homens e mulheres no âmbito de oportunidades de emprego, dentre outros, ainda vigora e é significativa.

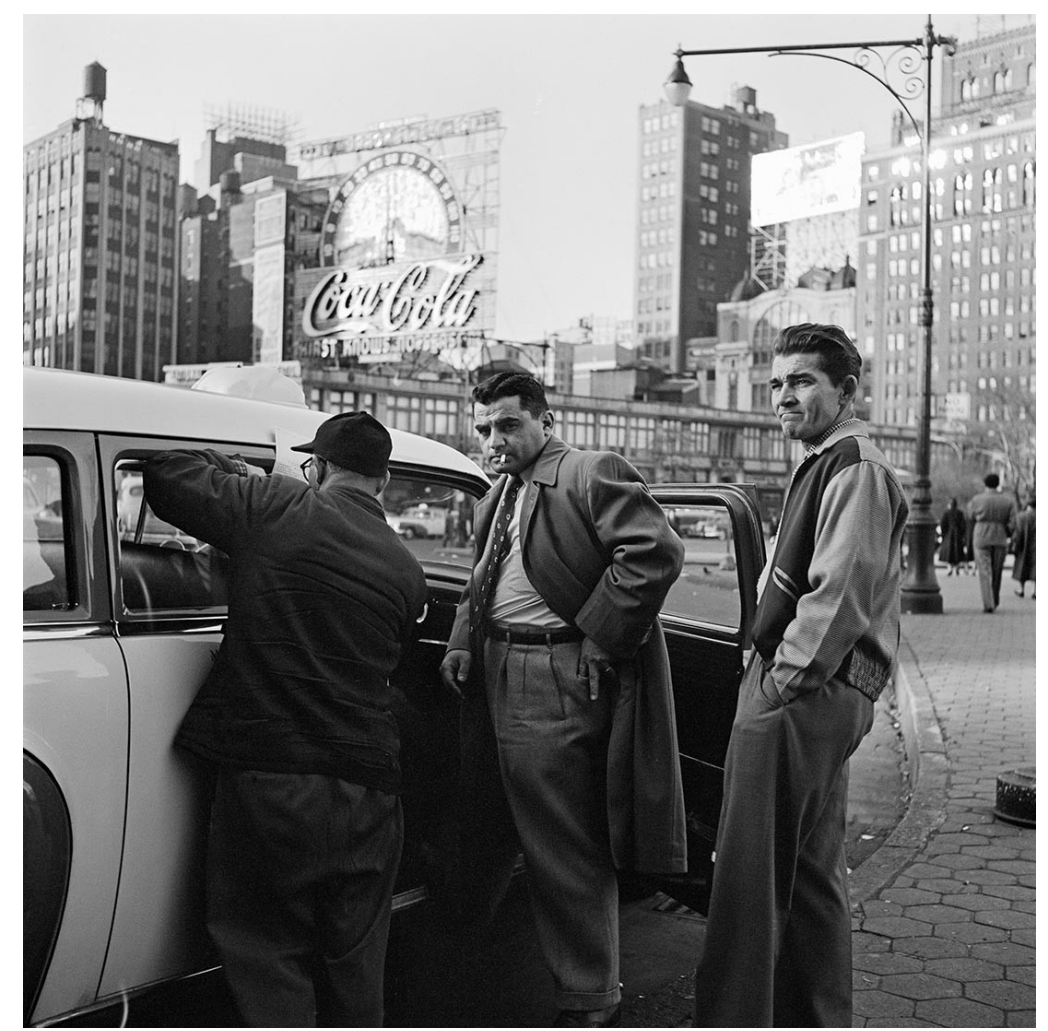

Figura 5: Vivian Maier, New York, NY, fotografia analógica, 1954.

Outro ponto a ser observado nas fotografias de Maier é o processo de espetacularização das cidades modernas. Os prédios que compõem os cenários de muitas de suas fotos (Figura 5) mostram uma Nova Iorque em franco desenvolvimento e crescimento vertical, no início dos "Anos Dourados", pós Segunda Guerra. Porém, esta "super-revitalização" foi bem mais excludente do que podemos avaliar através da imagem. A espetacularização se transformou numa "faca de dois gumes" para as relações do indivíduo com a cidade, uma vez que "o espetáculo não é um conjunto de imagens, mas uma relação social entre pessoas, mediada por imagens" (DEBORD, 1997, p.14). Como defende Debord, o espetáculo se constituiu como um modelo de vida dominante, uma vida voltada para o consumo que atraiu muitas pessoas, ao mesmo tempo em que as afastou de uma relação real com o meio em que vivem:

As ideias situacionistas sobre a cidade, principalmente contra a transformação dos espaços urbanos em cenários para espetáculos turísticos, levam a uma hipótese clara: a existência de uma relação inversamente proporcional entre espetáculo e participação popular. $\mathrm{Ou}$ seja, quanto mais espetacular forem as intervenções urbanísticas nos processos de revitalização urbana, menor será a participação da população nesses processos e vice-versa (JACQUES, 2009, p.3). 


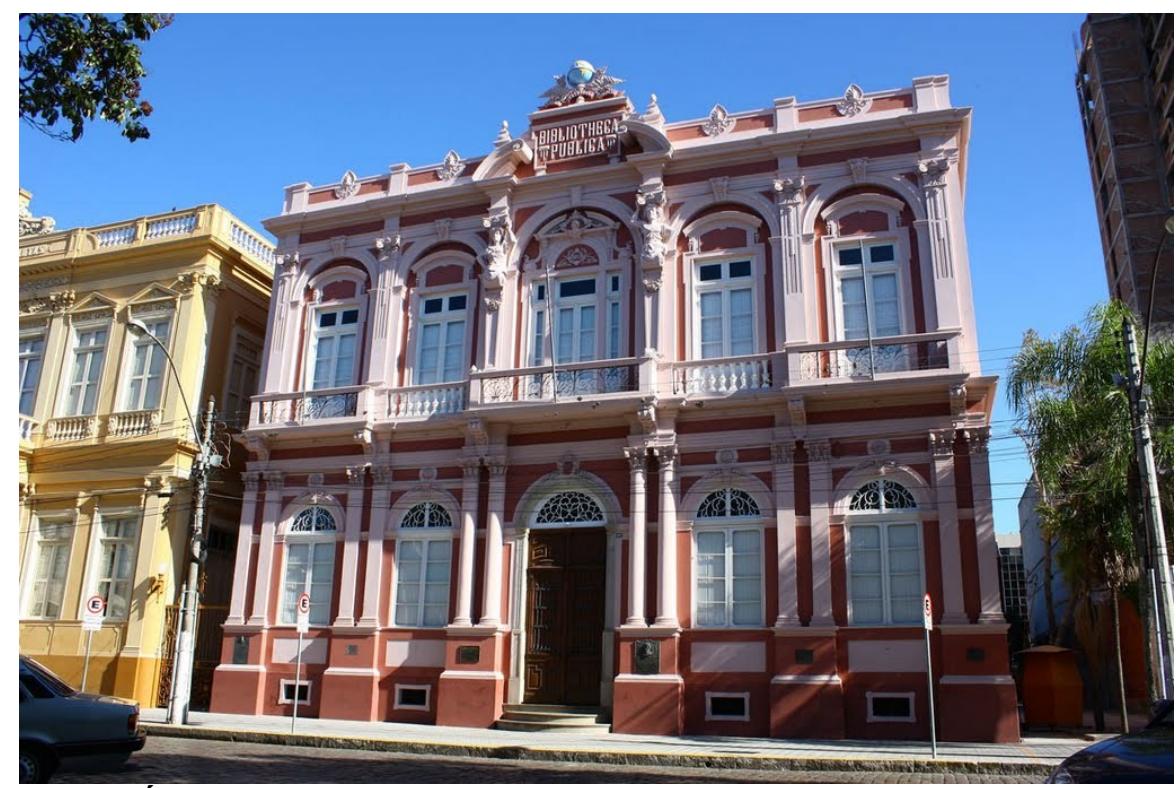

Figura 6: Ítalo Franco, Biblioteca Pública de Pelotas, fotografia digital, 2014.

$\mathrm{Na}$ contemporaneidade identificamos ainda processos de espetacularização das cidades brasileiras, entretanto, outras discussões sobre o espaço urbano são levantadas. Caminhar pela cidade de Pelotas, por exemplo, nos permite identificar uma preocupação com a preservação do patrimônio histórico (Figura 6), e, por consequência, da memória comunitária. Porém, se percebe que o centro conservado com grandes prédios restaurados, sua praça e as ruas no entorno se configuram como um belo "cartãopostal", que são visitados, em sua maior parte por turistas, caracterizando uma área privilegiada de beleza urbana. Isso, de certo modo produz o apagamento dos arredores da cidade, que se mantêm inexplorados e sem merecer a atenção devida por parte do poder público. É como se uma divisão fosse feita: o centro visível para os turistas e o seu entorno para a população local.

\section{CONSIDERAÇÕES FINAIS}

A distância, ou descolamento, entre sujeito e objeto, entre prática profissional e vivência-experiência física da cidade, se mostra desastrosa ao se eliminar o que o espaço urbano possui de mais urbano, que seria precisamente seu caráter humano, ou pior, ao se eliminar o que de mais humano tem o homem: seu próprio corpo. Nosso corpo físico e o corpo da cidade, e as suas respectivas carnes, se encontram, se tateiam e se atritam nos espaços públicos urbanos (JACQUES, 2005, p.9).

Temos consciência de que "a necessidade de confirmar a realidade e de realçar a experiência por meio de fotos é um consumismo estético em que todos, hoje, estão viciados. As sociedades industriais transformam seus cidadãos em dependentes de imagens" (SONTAG, 2004, p. 18). E é justamente esse o motor das atividades do PhotoGraphein, e da opção pela Carto/Foto/Graphia como um meio que nos possibilita (re)descobrir a cidade através da deriva. Isso nos auxilia na reflexão e problematização das relações que mantemos com os espaços urbanos, pensando a fotografia como uma mediadora simbólica dessas relações. 
Posicionados como observadores atentos do cotidiano, buscamos as conexões entre arte e cidade, (re)significando ideias e comportamentos, (re)visitando imaginários e (re)construindo a história pelo viés da produção fotográfica. E foi esse movimento de aproximação atemporal que buscamos elaborar neste artigo. As imagens apresentadas de Vivian Maier demonstram um olhar atento às interações humanas com o meio, e simbolicamente nos conectam há um tempo que está na base do nosso, cujas influências ainda reverberam. Consideramos que em um mundo dominado pela distração, o envolvimento direto com as cidades, além de estimular o sentido de pertencimento, permite também a consciência identitária que nos une significativamente ao tecido social.

\section{REFERÊNCIAS}

ARANTES, Antonio A. O Espaço da Diferença. Campinas/SP: PAPIRUS, 2000.

BRANDÃO, C.M.M. Das derivas do graffiti às (de)marcações urbanas do imaginário. Anais Eletrônicos do II Congresso Internacional de História Regional, 2013.

BRANDÃO, C.M.M. Universos Imaginados: Sobre Identificações reflex(ivas). Anais VII Congresso Internacional de Pesquisa (Auto)Biográfica, 2016.

D'ANGELO, Martha. A Modernidade Pelo Olhar de Walter Benjamin. Rev. Estudos Avançados 20, 2006.

DEBORD, Guy. A Sociedade do Espetáculo. Rio de Janeiro/RJ CONTRAPONTO, 1997.

DURAND, Gilbert. O imaginário: ensaio acerca das ciências e da filosofia da imagem. Rio de Janeiro: DIFEL, 2001.

JACQUES, Paola Bereinstein. Errâncias Urbanas: A Arte de Andar Pela Cidade. Arqtexto 7, 2005.

KASTRUP, Virgínia. PASSOS, Eduardo. ESCÓSSIA, Liliana. Pistas do Método da Cartografia. Porto Alegre/RS: Sulina, 2015.

MALOOF, John; SISKIEL, Charlie. FINDING, Vivian Maier. Documentário. Produção: John Maloof, Charlie Siskiel, 2013.

ORTIZ, Renato. Walter Benjamin e Paris - individualidade e trabalho intelectual. Rev. Sociol. 12 USP, S. Paulo, 2000.

ROUILLÉ, André. A Fotografia: Entre Documento e Arte Contemporâna. São Paulo: SENAC, 2009

SONTAG, Susan. Sobre Fotografia. São Paulo/SP: Companhia das Letras, 2004. 